\title{
Psychiatric Morbidities among Attenders of an Islamic Spiritual Healing Centre in Malaysia
}

\author{
Khadijah Hasanah Abang Abdullah ${ }^{\mathrm{a}}$, Suriati Mohamed Saini ${ }^{\mathrm{b}}$, Shalisah Sharip ${ }^{\mathrm{b}}$, Mohamed Hatta Shaharom \\ ${ }^{a}$ Faculty of Medicine \& Health Sciences, Universiti Sains Islam Malaysia, 56100 Kuala Lumpur, Malaysia \\ ${ }^{b}$ Department of Psychiatry, Universiti Kebangsaan Malaysia Medical Centre, Kuala Lumpur, Malaysia \\ ${ }^{c}$ Faculty of Medicine, Cyberjaya University College of Medical Sciences (CUCMS), Cyberjaya, Selangor, \\ Malaysia
}

\section{ABSTRACT}

Introduction: Traditional medicine which includes Islamic faith healing centre is still an important place to seek treatment whether for psychiatric reasons or others. This study aims to determine the prevalence of psychiatric illness among attenders of an Islamic spiritual healing centre and to understand patients' illness attribution and their religiosity. Methods: A cross-sectional study was done with a systematic random sampling to obtain the prevalence of psychiatric illness which was diagnosed using Malay version of Mini International Neuropsychiatric Interview (M.I.N.I). Religiosity was measured using Hatta Islamic Religiosity Scale 1996 (HIRS96) and illness perception using Brief Illness Perception Questionnaire (BIPQ). Results: The prevalence of psychiatric illness among the attenders was 53.5\%. Depressive disorder were more prevalent $(41.5 \%)$ followed by anxiety disorder $(28.3 \%)$, bipolar disorder $(16.8 \%)$ and psychotic disorders $(5.9 \%)$. More than half $(58.8 \%)$ of attenders attributed their illness to supernatural causes but there were no significant difference between those with psychiatric illness and those without in terms of their attribution to supernatural causes, $\mathrm{p}=0.197$.Generally, the patients had a higher religiosity score. Conclusion : This high prevalence shows a need for collaboration with the spiritual healing practitioners to improve delivery of treatment to patient and this would be a more holistic approach.

KEYWORDS: Spirituality, Spiritual Healing, Traditional Medicine, Religiosity, Psychiatric Morbidity

\section{INTRODUCTION}

The Islamic spiritual healing technique is one of the techniques of the complementary or traditional medicine that is very popular in Malaysia. Traditional medicine is a broad term that encompasses traditional medicine system or practices that are based on theories, beliefs and experiences indigenous to different cultures. ${ }^{1}$

It can be divided into medication therapies (using herbal medicine) or non-medication which includes acupuncture and spiritual or faith therapy. Islamic spiritual healing uses mainly prayers and the practitioners are normally religious people in the community. Traditional healers or better known as bomoh or pawang in Malaysia, are influenced by the animistic, Hindu and Islamic elements in their

Corresponding author:

Dr Shalisah Sharip

Department of Psychiatry,Universiti Kebangsaan

Malaysia Medical Centre (UKMMC)

Jalan Yaacob Latif, Bandar Tun Razak, Cheras,

56000 Kuala Lumpur, Malaysia

Tel: +603-91456143 Fax: +603-91456681

Email : shalisah@ppukm.ukm.edu.my techniques and practices. $^{2}$ This combination of therapy is not accepted by orthodox Islamic therapeutic teachings and practices. We prefer to use the term "spiritual" instead of "faith" in this healing technique because spirituality is more encompassing than faith and it is one of the four domains of the bio-psycho-socio-spirtual holistic treatment model.

The fundamental belief in Islam is God is One and $\mathrm{He}$ is the Most Powerful. It is written in the Quran which is the Islamic Holy Book, "And when I am ill, it is He who cures me." (Ash-Shu'araa' 26: 80) ${ }^{3}$ This translates to God being the ultimate healer. By holding on to this belief, prayer to God asking for recovery is the key. However, doctors, medication and even spiritual healing practitioners are instruments of the mercy of God in the healing process.

From the psychiatric services perspective, it has been an ongoing issue where psychiatric patients would consult a traditional healer before seeking medical help. A local study by Razali in 2000 found that about $69 \%$ of patients had visited a traditional healer before seeking psychiatric help. ${ }^{4}$ A comparison in a psychiatric and medical outpatient departments showed higher rates of 
psychiatric patients consulted a traditional healer as compared to their medical counterparts $(73.1 \%$ vs $25 \%)^{5}$ This may result in treatment delay 4,6 , although another study done in urban setting in Malaysia had shown no significant delay in treatment among first episode psychosis. ${ }^{7}$

Even after receiving psychiatric treatment, some patients still consult the traditional or spiritual practitioners for advice. This sometimes result in poor compliance ${ }^{8}$ to treatment as some practitioners advice against medical treatment. They attribute the illness to supernatural agents e.g. witchcraft or dissonance between a person's desires and their religions' teachings ${ }^{9}$ thus implying that medical treatment is not the solution. However, some practitioners know their limits and would suggest the patient to seek medical treatment if it is beyond their expertise. ${ }^{7}$

Studies have highlighted the advantages of traditional or faith practitioners in terms of affordability, availability and accessibility as compared to our modern or contemporary medicine. ${ }^{10}$ Interestingly, they have also shown to give more support and possibly some psychotherapy as well to the patients. ${ }^{10}$ Discussion on traditional medicine and psychiatric illness is a concern worldwide especially in the poor and developing countries. $^{9-11}$ In Malaysia, there have been studies investigating hospital patients who have visited traditional or faith practitioners. ${ }^{4,5,12}$

But to the best of our knowledge, there has not been a study that investigates psychiatric illnesses in the traditional or spiritual practitioners setting in Malaysia. The aim of the study was to investigate the prevalence of psychiatric illness among those attending an Islamic spiritual healing centres. We also hypothesize that those diagnosed to have mental illness would attribute their illness to supernatural causes and have a lower religiosity score.

\section{MATERIALS AND METHOD}

\section{Study design}

This is a cross-sectional study which was conducted from August 2015 till March 2016. The sample size calculation of this study was 368 patients, which was based on a study in Pakistan, which found that $61 \%$ of those who sought help from faith healers had psychiatric diagnosis. The inclusion criteria were attenders (1) age 18-60 (2) able to read and write in Malay or English (3) given written consent. The exclusion criteria were (1) mentally subnormal clinically (2) patients having acute illness that required urgent attention.

\section{Study site}

The study site is Darussyifa,13 which means the house of healing in Arabic. It is one of the most established spiritual healing centres in Malaysia with 83 branches all over the country. The main branch was chosen because of its popularity where patients from other parts of the country would come for treatment and they have a large number of patients. It has been in operation since 1991. It opens 7 days a week, with 3 sessions (morning, afternoon and night) almost everyday. Darussyifa' has also been registered under the Traditional and Complementary Medicine division of the Ministry of Health. Apart from providing treatment, Darussyifa' also produces its own graduates of faith healers. They have to attend classes and sit for examinations to pass as a qualified spiritual healing practitioner.

\section{Study procedure}

The attenders of this centre were selected using systematic random sampling. This was possible as the centre had a registration system where the patient would write their name and relevant details. As the centre had many faith healing practitioners and patient were keener to be interviewed while waiting for their turn, every $10^{\text {th }}$ patient were selected for the study. Eligible subjects were ask to answer three self-administered questionnaire which are the sociodemographic, Hatta Islamic Religiosity Scale 1996 (HIRS96) and Brief Illness Perception Questionnaire (BIPQ) and were interviewed by the researcher, KHAA, using Mini International Neuropsychiatric Interview (MINI). KHAA had attended training to use MINI in UKM.

\section{Ethical consideration}

This study was conducted at the main branch of a faith healing centre named Darussyifa' which is in Bangi, Selangor, Malaysia. Ethical approval was obtained from the Universiti Kebangsaan Malaysia Medical Centre (UKM) Medical Ethics Committee prior to the study. A written permission was also granted by the chairman of the spiritual healing centre. Those patients who were diagnosed with psychiatric illness were offered referral to psychiatric services.

\section{Study instruments}

\section{Sociodemograhic questionnaire}

A sociodemographic questionnaire was given to obtain information on age, gender, ethnic group, marital status, education level, employment status and current occupation.

\section{Hatta Islamic Religiosity Scale 1996 (HIRS96) $^{14}$}

As it is an Islamic faith healing centre, an Islamic religiosity scale was chosen which was developed by a local researcher who is also involved in this study, MHS. This questionnaire assesses a person's knowledge, practice, Quran reading and attitude towards enjoining good and forbidding evil. A reliability and validity study had been conducted for this scale and showed high interrater reliability 
(0.891 and 0.90$)$ and that the measure was valid in discriminating between the two groups that they studied $(p<0.05)$. (Hanafiah M Salleh et al. 2000). The higher score indicates higher index of religiosity.

\section{Brief Illness Perception Questionnaire ${ }^{15}$}

It is a nine-item scale designed to rapidly assess the cognitive and emotional representations of illness. The items were developed by forming one question that best summarised the items contain in each subscale (a total of 80 items) of the revised Illness Perception Questionnaire ( IPQ-R). ${ }^{16}$ The Brief IPQ showed good test-retest reliability and concurrent validity when tested with relevant measures.

There is no cut-off points but a higher score indicates more threatening view of the studied illness. Item 9 of BIPQ assesses cause or illness attribution. For this study, it has been grouped into supernatural and non-supernatural causes. The researchers had translated and validated the Malay version of the BIPQ.

\section{Mini International Neuropsychiatric Interview (M.I.N.I) $)^{17}$}

The M.I.N.I was designed as a brief structured interview for the major axis 1 psychiatric disorders in DSM-IV and ICD-10. Studies show that M.I.N.I has similar reliability and validity properties, but can be administered in much shorter period of time than SCID-P and the CIDI. Furthermore, it can be used after a brief training session.

\section{Statistical analysis}

The data were analyzed using IBM Statistical Package for Social Sciences (SPSS)version 23. Descriptive analysis was conducted. Univariate analysis was done using Chi-square analysis for categorical data. For continuous data, t-test for parametric and Mann-Whitney test for nonparametric data were used where appropriate.

\section{RESULTS}

A total of 370 patients were interviewed but 2 withdrew their consent by email a day after being interviewed and 11 did not complete the questionnaires as their names were called during the interview session and patient did not return to complete the interview after their consultation with the practitioner. This is because either they were too weak after the treatment or had to leave because of the time. So, a total of 357 patients were available for analysis.
The patients had a mean age of 37 . There were more females $(75.1 \%)$ than males $(24.9 \%)$. All patients were Muslims although there were nonmuslim who attended the centre. Majority were Malays (98.3\%) but there were also Chinese $(0.3 \%)$, Indian $(0.6 \%)$ and others $(0.8 \%)$. There was no significant gender difference in terms of age, race, educational level, diagnosis and illness attribution. The participants' sociodemographic data are presented in Table I.

The prevalence of psychiatric illness among attenders of this faith healing centre was $53.5 \%$. Depressive disorder had the highest prevalence (41.5\%) followed by anxiety disorders (28.3\%), bipolar disorders (16.8\%) and psychotic disorders (5.9). Some of the patients had multiple diagnosis with $88(24.6 \%)$ having one diagnosis , $53(14.8 \%)$ had dual diagnoses, 24 (6.7\%) fulfilled 3 diagnoses and $26(7.4 \%)$ fulfilled 4 or more diagnoses. The prevalence of psychiatric diagnoses are presented in Table II.

About $58.8 \%$ patients attribute their illness to supernatural causes while $140(39.2 \%)$ attributes it to non-supernatural causes. This supernatural causes include disturbance from devil or jinn, having saka (a belief that jinn may be inherited in the lineage) and santau (a form of black magic that can make a person ill).

Non-supernatural causes include medical problems, genetic, environmental stressors and etc. Nonetheless, there was no significant difference between those with psychiatric illness and those without psychiatric illness in terms of their illness attribution to supernatural causes,$\left(\chi^{2}=1.66, d f=1\right.$, $p=0.197)$.

Overall, the mean score for illness perception scale using BIPQ was $41.78 \pm 8.44 \mathrm{SD}$, and the religiosity score using HIRS96 was $64.94 \pm 9.53$ SD, which indicates a more threatening view of illness and higher religiosity score, respectively.

An independent-sample $\mathrm{t}$-test was conducted to compare religiosity between those attending the faith healing centre with psychiatric illness and those who does not. No significant difference was found in terms of religiosity, $t(355)=1.941, p=0.53$. As the illness perception scores were not normally distributed, Mann-Whitney's U test was used. Those with psychiatric diagnosis view their illness as more threatening compared to those who does not have a psychiatric diagnosis, $\mathrm{U}(18)=8897.0, \mathrm{Z}=-6.97$, $p<0.001$. 
Table I: Sociodemographic data with gender comparison

\begin{tabular}{|c|c|c|c|c|}
\hline Sociodemographic factor & Male $\mathrm{n}(\%)$ & Female $\mathrm{n}(\%)$ & Total & $P$ value \\
\hline \multicolumn{5}{|l|}{ Age (years) } \\
\hline Mean (SD) & $37.36(11.09)$ & $37.62(11.455)$ & $37.55(11.35)$ & 0.854 \\
\hline \multicolumn{5}{|l|}{ Race } \\
\hline Malay & $87(24.4)$ & $264(73.9)$ & $351(98.3)$ & \\
\hline Chinese & 0 & $1(0.3)$ & $1(0.3)$ & 0.772 \\
\hline Indian & $1(0.3)$ & $1(0.3)$ & $2(0.6)$ & \\
\hline Others & $1(0.3)$ & $2(0.6)$ & $3(0.8)$ & \\
\hline \multicolumn{5}{|l|}{ Marital status } \\
\hline Single & $17(4.8)$ & 71(19.9) & $88(24.6)$ & \\
\hline Married & $70(19.6)$ & $171(47.9)$ & $241(67.5)$ & $0.031^{*}$ \\
\hline Divorced & $2(0.6)$ & $15(4.2)$ & $17(4.8)$ & \\
\hline Widow/Widower & 0 & $11(3.1)$ & $11(3.1)$ & \\
\hline \multicolumn{5}{|l|}{ Educational level } \\
\hline No formal education & 0 & $2(0.6)$ & $2(0.6)$ & \\
\hline Primary-incomplete & 0 & $1(0.3)$ & $1(0.3)$ & \\
\hline Primary-complete & $1(0.3)$ & $5(1.4)$ & $7(1.7)$ & 0.155 \\
\hline Secondary-PMR & $4(1.1)$ & $8(2.2)$ & $12(3.4)$ & \\
\hline Secondary-SPM & $25(7.0)$ & $72(20.2)$ & $97(27.2)$ & \\
\hline Secondary-STPM & $1(0.3)$ & $18(5.0)$ & $19(5.3)$ & \\
\hline Tertiary -Diploma & $25(7.0)$ & $66(18.5)$ & $91(25.5)$ & \\
\hline Tertiary-Degree & $33(9.2)$ & $81(22.7)$ & 114(31.9) & \\
\hline Tertiary-PhD & 0 & $15(4.2)$ & $15(4.2)$ & \\
\hline \multicolumn{5}{|l|}{ Employment } \\
\hline Never & $3(0.8)$ & $22(6.2)$ & $25(7.0)$ & \\
\hline Not employed & $9(2.5)$ & $59(16.5)$ & $68(19.0)$ & $0.047^{*}$ \\
\hline Retired & $3(0.8)$ & $11(3.1)$ & 14(3.9) & \\
\hline Part-time & $2(0.6)$ & $6(1.7)$ & $8(2.2)$ & \\
\hline Self-employed & $21(5.9)$ & $40(11.2)$ & 61(17.1) & \\
\hline \multicolumn{5}{|l|}{ Current job } \\
\hline Professional/technical/admin & $39(11.1)$ & $103(29.4)$ & $142(39.8)$ & \\
\hline Agriculture/fisheries/forestry & 0 & $1(0.3)$ & $1(0.3)$ & \\
\hline Military/police/fireman & $3(0.9)$ & $1(0.3)$ & $4(1.1)$ & $<0.001^{*}$ \\
\hline Factory & $3(0.9)$ & $3(0.9)$ & $6(1.7)$ & \\
\hline Clerical/sales & $8(2.3)$ & $21(6.0)$ & $29(8.1)$ & \\
\hline Services (maid, waiter, security) & $2(0.6)$ & $8(2.3)$ & $10(2.8)$ & \\
\hline Housewife & $1(0.3)$ & $61(17.4)$ & $62(17.4)$ & \\
\hline Own business & $19(5.4)$ & $32(9.1)$ & $51(14.3)$ & \\
\hline Student & $8(2.3)$ & $21(6.0)$ & $29(8.1)$ & \\
\hline Others & $4(1.1)$ & $12(3.4)$ & $16(4.5)$ & \\
\hline \multicolumn{5}{|l|}{ Diagnosis } \\
\hline No psychiatric illness & $42(11.8)$ & $124(34.7)$ & $166(46.5)$ & 0.880 \\
\hline Psychiatric illness & $47(13.2)$ & $144(40.3)$ & $191(53.5)$ & \\
\hline \multicolumn{5}{|l|}{ Illness attribution } \\
\hline Non supernatural & $40(11.4)$ & $100(28.6)$ & $140(40.0)$ & 0.156 \\
\hline Supernatural & $46(13.1)$ & $164(46.9)$ & $210(60.0)$ & \\
\hline
\end{tabular}


Table II: Prevalence of psychiatric diagnoses amongst Islamic spiritual healing centre attenders

\begin{tabular}{|c|c|c|}
\hline Diagnosis & $\mathrm{N}$ & $(\%)$ \\
\hline \multicolumn{3}{|l|}{ Major Depressive Disorder } \\
\hline None & 209 & 58.5 \\
\hline Current & 76 & 21.3 \\
\hline Past & 37 & 10.4 \\
\hline Recurrent & 35 & 9.8 \\
\hline \multicolumn{3}{|l|}{ Bipolar Disorder } \\
\hline None & 297 & 83.2 \\
\hline Manic & 9 & 2.5 \\
\hline Hypomanic episode & 17 & 4.8 \\
\hline Hypomanic symptoms & 34 & 9.5 \\
\hline \multicolumn{3}{|l|}{ Panic Disorder } \\
\hline None & 271 & 75.9 \\
\hline Panic with agoraphobia & 23 & 6.4 \\
\hline Panic without agoraphobia & 22 & 6.2 \\
\hline Agoraphobia & 20 & 5.6 \\
\hline Lifetime panic disorder without agoraphobia & 10 & 2.8 \\
\hline Lifetime panic disorder with agoraphobia & 11 & 3.1 \\
\hline \multicolumn{3}{|l|}{ Social Phobia } \\
\hline None & 342 & 95.8 \\
\hline Generalized & 12 & 3.4 \\
\hline Specific & 3 & 0.8 \\
\hline \multicolumn{3}{|l|}{ Obsessive Compulsive Disorder } \\
\hline None & 346 & 96.9 \\
\hline Current & 11 & 3.1 \\
\hline \multicolumn{3}{|l|}{ Post Traumatic Stress Disorder } \\
\hline None & 351 & 98.3 \\
\hline Current & 6 & 1.7 \\
\hline \multicolumn{3}{|l|}{ Psychotic Disorder } \\
\hline None & 336 & 94.1 \\
\hline MDD with lifetime psychosis & 9 & 2.5 \\
\hline MDD with current psychosis & 5 & 1.4 \\
\hline Lifetime psychosis & 2 & 0.6 \\
\hline Current psychosis & 5 & 1.4 \\
\hline \multicolumn{3}{|l|}{ Generalized Anxiety Disorder } \\
\hline None & 323 & 90.5 \\
\hline Current & 34 & 9.5 \\
\hline
\end{tabular}

\section{DISCUSSION}

In the present study, more than half of the participants had diagnosable psychiatric illness. This finding is consistent with a study done in Pakistan ${ }^{18}$ but with a slightly higher rate there. This reflects the importance of collaboration between mental health practitioner and spiritual healing practitioners. People still visit spiritual healing practitioner because of many factors. Religion is possibly one of the main factors of influence as reflected by the overall higher religiosity score.

Religion is very important in many peoples' lives and it does affect how a person view their life and to a certain extent, view their illness. It affects their coping skills ${ }^{19}$ and help seeking behaviour. A study by Corrigan found that religiosity is positively associated with psychological well-being and improved psychiatric symptoms in mentally ill patients. ${ }^{20}$ Measuring religiosity is not easy as it is very subjective. In Islam, one would argue that only God can determine how religious a person is because it is related to a person's sincerity. Despite this difficulty, many researchers have tried to propose scales to measure a person's religiosity. ${ }^{21,22}$ The Hatta Islamic Religiosity Scale 1996 (HIRS96) measures four dimensions i.e. knowledge, practice, Quran reading and enjoining good and forbidding evil which the authors find reflects a person religiosity index.

The higher overall religiosity score found in the respondents in this study may show that when a person is more religious they tend to seek help with Islamic spiritual practitioner because of the belief that God is the ultimate healer. On the other hand, some non-practicing Muslim patients reported that the healing process of the illness has made them become more religious. This is mainly due to heeding the advice of Islamic spiritual practitioner that patients must adhere to Islamic teachings if they were to see improvement in the illness that they suffer from, and general betterment in life.

A recently published qualitative study on depression and spirituality showed that depressed patients has religious needs and existential needs which includes 
calmness, hope and meaning of illness, especially in times of crisis. ${ }^{23}$ Knowing the importance of religion or spirituality in helping a patient recover, some researchers have proposed an integrated approach in delivering psychotherapy. This spiritually oriented approach must be tailored to a person's issue e.g patient who becomes depressed because of guilt, may benefit from therapy focusing on forgiveness in a religious context. ${ }^{24}$

A systematic review was done on the effectiveness of traditional healer on treating mental disorders which included 32 papers from 20 countries. They concluded that the studies were generally of poor quality but there were evidence that it was helpful in mild psychiatric illnesses like depression and anxiety. ${ }^{25}$

Affective disorders showed higher prevalence among the attenders as compared to psychotic disorders. Studies from other countries like Saudi Arabia ${ }^{26}$ and Pakistan ${ }^{18}$ also showed similar pattern. Some factors may have influenced this pattern. Patient with affective disorders tend to appreciate the counselling therapy that the faith healing practitioner offers. ${ }^{19,27}$ They are able to confide their problems and the advice to improve their spiritual strength are generally favorable and acceptable. The practitioner also encourages support from the patient's family or relatives.

For patients with psychotic disorders, they can be too disturbed or difficult for family to bring them for treatment and if they did come, they might have been seen as an acute case and would not be available to be interviewed for the research or refuse interview as they cannot complete the questionnaires. This is one limitation of this research. However, a local study found that among those with first episode psychosis, 54\% had at least one contact with traditional healer before seeking psychiatric help. ${ }^{12}$

Stigma is still a huge concern with respect to psychiatry. The researcher had the experience of being turned down for the interview because coming from a psychiatry department and investigating mental illness. Some are reluctant to join the study because they are worried they might be labelled as "mentally ill". Two patients completed the questionnaire but emailed the researchers the following day to withdraw their consent. This may be due to their families' perceived stigma of mental illness.

Anecdotally, the researcher found that most of the patients interviewed and was diagnosed with psychiatric illness, had never sought treatment from psychiatric services because of lack of information of where and how to get help. They also believed that the treatment they received from the spiritual healing practitioner was helpful. However, most of them were still symptomatic albeit fairly manageable. This spiritual therapy can be protective as very few patients reported suicidal thoughts. A recent study in Iran showed that strong religious belief was a protective factor for suicide in those with less stressful life events. ${ }^{28}$

This study found no difference in attribution to supernatural causes between those with and without psychiatric illness. This shows that medical conditions can also be perceived to be caused by supernatural agents. Hence, we do see patients with cancer $^{29}$ or tuberculosis ${ }^{30}$ seeking treatment from traditional or faith-healing practitioners. A review done by Lim et al in 2014 revealed that people attribute psychiatric symptoms to jinn not only for psychotic symptoms but also mood, obsessive compulsive disorder and even epilepsy. ${ }^{31}$

Another limitation of this study is that it was done only at one centre. This centre is situated in the urban area which is reflected on the higher educational level of the attenders. However, this also means that seeking traditional medicine is not a thing of the past, but still much prevalent even today.

A collaboration would give the patient a more holistic treatment that would facilitate recovery. An experience from The Hague ${ }^{31}$ where they provide an Imam or a religious counsellor in the psychiatric setting, found that it helps the patient to share and improve their acceptance of the treatment. One of the concern raised about prospect for collaboration is the unethical methods of treatment that some traditional healer would impose on the patient i.e. unethical practices, lack of standardization and lack of evidence for efficacy. ${ }^{10}$ In Malaysia, we have many spiritual healing practitioners from different groups or societies and we also have numerous traditional healers whose treatment approaches vary.

A Traditional and Complementary Medicine (TCM) division has been established in the Malaysian Ministry of Health since 2004. The TCM incorporate certain types of practice in the government hospital e.g. acupunture and postnatal massage. ${ }^{32}$ "Islamic Medical Practice" or Islamic spiritual healing is recognized by the TCM division and Darussyifa is one of the practising bodies that has been appointed by the TCM division to represent and assist in their plan to regulate the TCM practice in Malaysia. However, Islamic medical practice has not been included in the "integrated hospital programme".

We suggest working with those who have been registered with the TCM division. As this study centre is very organized in terms of its establishment and treatment methodology, we suggest engaging them in doing a clinical trial to assess efficacy of a more holistic treatment. Researchers in South Africa highlighted important points to create partnership between these two systems, which includes focusing on the "point of intersection" and re-orientating the medical health 
practitioner in a "meaning-centred" approach that entertains the diverse cultural or spiritual attributions of illness. ${ }^{33}$ We hope in the future, the faith healing practitioner would be able to refer patients to us and vice versa or have visiting psychiatrist to their centre or visiting spiritual healing practitioner to the psychiatry wards.

\section{CONCLUSION}

Patients will continue to visit spiritual healing practitioners to seek help for their health problem ranging from illnesses from the fields of psychiatry to medicine. Understanding the functions of these practitioners in providing spiritual treatment to the public would encourage the collaboration between health authorities and them. This will augur well for a holistic approach in the treatment of the patients.

\section{ACKNOWLEDGEMENTS}

The authors would like to thank Darussyifa's staffs and patients for their cooperation and support for the research. The authors would also like to acknowledge Universiti Kebangsaan Malaysia for the grant support received under FF-2014-398 Dana Fundamental PPUKM.

\section{Conflicts of interest \\ None declared}

\section{REFERENCES}

1. Traditional and complementary medicine. World Health Organization; 2015.

2. S. Othman SMS. Traditional Malay Healing In Malaysia: A Juristic Study. International Islamic University Malaysia; 2008.

3. The Holy Quran. Available from: www.quran.com

4. Razali SM, Najib MA. Help-seeking pathways among Malay psychiatric patients. Int J Soc $n$ Psychiatry. 2000 Jan;46(4):281-9.

5. Salleh MR. The consultation of traditional healers by Malay patients. Med J Malaysia. 1989 Mar;44(1):3-13.

6. Kumar L, Reddy PK, Babu S, Lokesh Kumar K. Delay in first psychiatric consultation and its reasons. AP J Psychol Med. 12(122):79-83.

7. Phang CK, Marhani M, Salina AA. Traditional Healers Are Causing Treatment Delay Among Patients With Psychosis In Hospital Kuala Lumpur: Fact Or Fallacy? ASEAN J Psychiatry. 2010;11(2):206-15.

8. Razali SM, Khan UA, Hasanah Cl. Belief in supernatural causes of mental illness among Malay patients: impact on treatment. Acta Psychiatr Scand. 1996 Oct;94(4):229-33.

9. Farooqi YN. Traditional Healing Practices Sought by Muslim Psychiatric Patients in Lahore, Pakistan. Int J Disabil Dev Educ. 2006;53(4):40115.

10. Ae-Ngibise K, Cooper S, Adiibokah E, Akpalu B, Lund C, Doku V, et al. "Whether you like it or not people with mental problems are going to go to them": a qualitative exploration into the widespread use of traditional and faith healers in the provision of mental health care in Ghana. Int Rev Psychiatry. 2010;22(6):558-67.

11. Sorsdahl KR, Flisher a J, Wilson Z, Stein DJ. Explanatory models of mental disorders and treatment practices among traditional healers in Mpumulanga, South Africa. Afr J Psychiatry. 2010;13(4):284-90.

12. Phang CK, Midin M, Abdul Aziz S. Prevalence \& experience of contact with traditional healers among patients with first-episode psychosis in Hospital Kuala Lumpur. Malaysian J Psychiatry. 2010; 19(2).

13. Official Webpage of Darussyifa. Available from: darussyifa.org

14. Salleh $\mathrm{H}$, Hatta M. Hatta Islamic Religiosity Scale 1996 (HIRS96)-A Reliability and Validity Study. Malaysia J Psychiatry. 2000;8(1):5-14.

15. Broadbent E, Petrie KJ, Main J, Weinman J. The Brief Illness Perception Questionnaire. J Psychosom Res. 2006;60(6):631-7.

16. Weinman J, Petrie KJ, Moss-morris R, Horne R. The illness perception questionnaire: A new method for assessing the cognitive representation of illness. Psychol Health. 1996;11(3):431-45.

17. Sheehan DV1, Lecrubier $Y$, Sheehan $K H$, Amorim $\mathrm{P}$, Janavs J, Weiller E, Hergueta $\mathrm{T}$, Baker R DG. The Mini-International Neuropsychiatric Interview (M.I.N.I.): the development and validation of a structured diagnostic psychiatric interview for DSM-IV and ICD-10. J Clin Psychiatry. 1998;59 Supplem (20):22-33.

18. Saeed K, Gater R, Hussain A, Mubbashar M. The prevalence, classification and treatment of mental disorders among attenders of native faith healers in rural Pakistan. Soc Psychiatry Psychiatr Epidemiol. 2000;35:480-5.

19. Hefti R. Integrating Religion and Spirituality into Mental Health Care, Psychiatry and Psychotherapy. Religions. 2011;2:611-27.

20. Corrigan PW, McCorkle B, Schwell B, Kidder K. Religion and spirituality in the lives of people with serious mental illness. Community Ment Health J. 2003;39(487-499).

21. Koenig HG, Büssing A. The Duke University Religion Index (DUREL): A Five-Item Measure for Use in Epidemological Studies. Religions. 2010;1(1):78-85.

22. Salleh MS. Religiosity in Development : A Theoretical Construct of an Islamic-Based Development. Int J Humanit Soc Sci. 2012;2 (14):266-74.

23. Nabil A, Mohamed Saini S, Nasrin N, Bahari R, Sharip S. "I can' t pray" - The spiritual needs of Malaysian Muslim patients suffering from depression. Int Med J Malaysia. 2016;15(1).

24. Peteet JR. Spiritually integrated treatment of depression: A conceptual framework. Depress Res Treat. 2012. 
25. Nortje G, Oladeji B, Gureje O, Seedat S. Effectiveness of traditional healers in treating mental disorders: a systematic review. The Lancet Psychiatry. 2016;3(2):154-70.

26. Alosaimi FD, Alshehri Y, Alfraih I, Alghamdi A, Aldahash S, Alkhuzayem $\mathrm{H}$, et al. Prevalence of psychiatric disorders among visitors to faith healers in Saudi Arabia. Pakistan J Med Sci. 2014;30(5):1-6.

27. Ali OM, Milstein G, Marzuk PM. The Imam's role in meeting the counseling needs of Muslim communities in the United States. Psychiatr Serv. 2005 Feb;56(2):202-5.

28. Baneshi MR, Haghdoost AA, Zolala F, Nakhaee N, Jalali M, Tabrizi R, et al. Can Religious Beliefs be a Protective Factor for Suicidal Behavior? A Decision Tree Analysis in a MidSized City in Iran, 2013. J Relig Health. 2016 Feb 29;1-9.

29. Al-Naggar RA, Bobryshev Y V, Abdulghani MAMM, Rammohan S, Al-Jashamy K. Knowledge and perceptions of cancer and cancer prevention among Malaysian traditional healers: a qualitative study. Asian Pac J Cancer Prev. 2012;13(8):3841-50.

30. Onyeneho NG, Chukwu JN. Traditional healers and tuberculosis control in southern Nigeria. Int Q Community Health Educ. 2010;31(2):187-202.

31. Lim A, Hoek HW, Blom JD. The attribution of psychotic symptoms to jinn in Islamic patients. Transcult Psychiatry. 2014;52(1):18-32.

32. Traditional \& Complementary Medicine Division. Ministry of Health Malaysia. Integrated Hospital. Available from : www.tcm.moh.gov.my

33. Campbell-Hall V, Petersen I, Bhana A, Mjadu S, Hosegood V, Flisher AJ. Collaboration between traditional practitioners and primary health care staff in South Africa: developing a workable partnership for community mental health services. Transcult Psychiatry. 2010;47 (4):610-28. 